\title{
Cultural-based visual expression: emotional analysis of human face via Peking Opera Painted Faces (POPF)
}

\author{
Ding Wang ${ }^{1} \cdot$ Jinsheng Kang ${ }^{1} \cdot$ Sheng-Feng Qin ${ }^{2}$. \\ Johannes Birringer ${ }^{3}$
}

Received: 30 January 2015 /Revised: 8 April 2015 / Accepted: 27 April 2015 /

Published online: 21 May 2015

(C) The Author(s) 2015. This article is published with open access at Springerlink.com

\begin{abstract}
Peking Opera as a branch of Chinese traditional cultures and arts has a very distinct colourful facial make-up for all actors in the stage performance. Such make-up is stylised in nonverbal symbolic semantics which all combined together to form the painted faces to describe and symbolise the background, the characteristic and the emotional status of specific roles. A study of Peking Opera Painted Faces (POPF) was taken as an example to see how information and meanings can be effectively expressed through the change of facial expressions based on the facial motion within natural and emotional aspects. The study found that POPF provides exaggerated features of facial motion through images, and the symbolic semantics of POPF provides a high-level expression of human facial information. The study has presented and proved a creative structure of information analysis and expression based on POPF to improve the understanding of human facial motion and emotion.
\end{abstract}

Keywords Facial expression · Facial motion · Emotion · Motion capture · Visual information · POPF

\section{Introduction}

The research considers current Peking Opera Painted Faces (POPF) and the performance of Peking Opera as a culture resource. The main objective of this study was to prove a new structure on information analysis of facial motion and expression. Because people's emotion

\section{Ding Wang}

Ding.Wang@brunel.ac.uk

1 Department of Design, College of Engineering, Design and Physical Sciences, Brunel University London, Uxbridge, Middlesex UB8 3PH, UK

2 Product/Industrial Design, Northumbria School of Design, Northumbria University, Newcastle upon Tyne, Tyne and Wear NE1 8ST, UK

3 Department of Arts and Humanities, College of Business, Arts and Social Sciences, Brunel University London, Uxbridge, UK 
influence the change of facial expressions, and facial information can be considered to be the external manifestations of emotion, thus efficiently recognise faces with emotional information is particularly important.

\subsection{Visual expression through Peking Opera Painted Faces (POPF)}

As an integrated stage performance art, the Peking Opera includes the vocal expression through its singing, the behavior expression through body movements, and the visual expression through painted face (See Fig. 1). The painting of POPF is particularly special; it contains the systemic symbolic semantics, and the semantics is the summary and refining of the Chinese traditional cultural elements.

The term "painted face" refers to the colourful facial make-up of an actor in traditional Peking Opera. Such make-up is worn mostly by actors playing roles known as Jing (painted faces) and Chou (clowns). It is stylised in form, colour, and pattern to symbolise the characteristics of specific roles [19]. Meanwhile, the symbolic semantics of POPF is composed by cultural elements including the facial colour, the type and the symbolic meaning.

Therefore, a knowledgeable audience, seeing a painted face, can tell easily whether it is a hero or a villain, a wise man or a fool, to be loved or hated, respected or ridiculed. Thus the painted face is quite appropriately called 'a mirror of the soul'. Painted faces were not created by the fancy of some individual. They are the creations of generations of dramatic artists, based on their observations and life experience and their analysis of the dramatic personae. Surely, the POPF is characterised by symbolism and exaggeration.

As Peking Opera developed, vividly painted faces enable audiences to see expressions clearly even from a distance, a great advantage in the days when dramatic performances were usually staged in the open air before large crowds. As a result, actors apply powder, ink, paint, and soot to their faces, creating the art of POPF.

The basic colours in modern POPF (See Table 11) are red, black, white, etc. Originally, colours were used just to emphasize or exaggerate a person's natural complexion. Despite POPF's riot of colours and strong decorative value, they are only a dozen types of painted faces. Types of POPF are based on the physical and mental characteristics of dramatic personae. For both practical and aesthetic purposes,
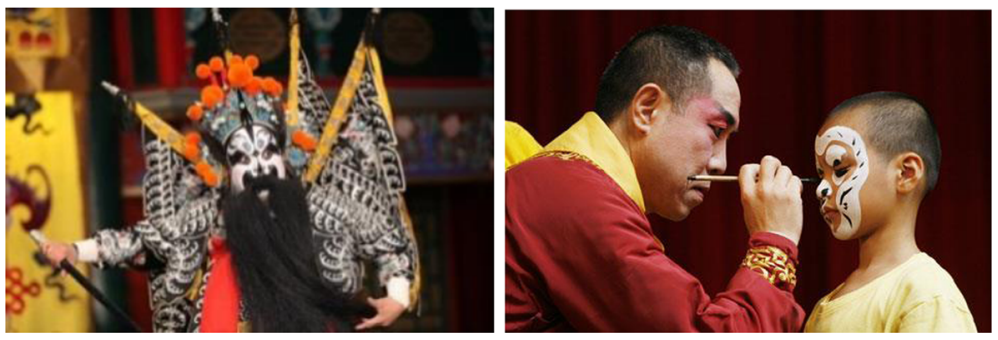

Fig. 1 The performance of Peking Opera with POPF and drawing POPF. Figure: Zhang Fei, from the novel of Romance of the Three Kingdoms, Figure: Monkey King, The Great Sage (the Equal of Heaven), from the novel of Pilgrimage to the West 
Table 1 Symbolic semanticics of POPF

\begin{tabular}{lll}
\hline Cultural elements & Description (In brief) & Meaning languages \\
\hline Facial colours & Black, red, white & $\begin{array}{c}\text { Colours are used to emphasize or exaggerate a person's } \\
\text { natural complexion. }\end{array}$ \\
Types & $\begin{array}{c}\text { Full face, Three-tile face, } \\
\text { Cross face }\end{array}$ & $\begin{array}{c}\text { Types are based on the physical and mental characteristics } \\
\text { of dramatics personae. }\end{array}$ \\
Symbolic meanings & $\begin{array}{c}\text { Patterns with strong } \\
\text { decorative value }\end{array}$ & $\begin{array}{c}\text { Deliberately exaggerate or distort the most typical features } \\
\text { while omitting less important details. }\end{array}$ \\
\hline
\end{tabular}

POPF must deliberately exaggerate the most typical features while omitting less important details (See Tables 1 and 2).

POPF as a branch of traditional Chinese cultures and arts has been known all over the world. However, modern young people do not truly understand that it is not only a painted accessory for the performance art, it is also created by design principles and methods.

Information and meanings can be effectively expressed through the colourful visual elements through POPF. Thus, the POPF is a classic visual expression of information transmission. The visual elements of POPF played the most effective role in the information transmittion.

\subsection{Visual information and visual expression}

People make contact with information all the time. Information design is used to help people grasp the information details in the shortest time and understand visual materials. Dirk Knemeyer thought that information design is an integrated vessel that collects other subjects so as to create an excellent information scheme. The famous information design expert, American Nathan Shedroff, separated design as information design, mutual design, and conscious design; he thought information design is to devise the message that the producers want to express, mutual design is made as the response of the customers, and conscious design needed to be planned from appreciation of the beauty and feeling psychology [12].

Table 2 An example of POPF with symbolic semantics

\begin{tabular}{|c|c|c|c|c|}
\hline $\begin{array}{l}\text { Illustration } \\
\text { and figure }\end{array}$ & $\begin{array}{l}\text { Cultural } \\
\text { elements }\end{array}$ & \multicolumn{2}{|l|}{ Description } & Meaning languages \\
\hline & $\begin{array}{l}\text { Facial } \\
\text { colour }\end{array}$ & & & Blue: valor and resolution \\
\hline$\Gamma$ & Type & & & $\begin{array}{l}\text { Three-tile face: } \\
\text { (The flowered Three-tile face) } \\
\text { A bold warrior or a green-wood hero }\end{array}$ \\
\hline $\begin{array}{l}\text { in } \\
\text { Stealing the } \\
\text { Imperial Steed }\end{array}$ & $\begin{array}{l}\text { Symbolic } \\
\text { meanings }\end{array}$ & $\mathrm{AS}$ & (1) & $\begin{array}{l}\text { Two halberds: Wrinkles } \\
\text { Yintang (The gall-shapeed figure): Prowess } \\
\text { Weapon pattern: The deadly two-hook weapon }\end{array}$ \\
\hline
\end{tabular}


Human feeling is combined with senses of vision, hearing, smelling, tasting and touching. According to the results of scientific research, $70 \%$ of the messages come from the sense of vision (See Fig. 2). So, academic circles are focused mainly on visual design, which is aimed at human visual senses. Thus, both visual and philosophical information are considered as the cultural access point [7].

Cross-cultural research on visual design is very active, but there is no unified and specific definition. Design of visual information is produced by visual medium for people to pass on messages, and the design of information is at its center, with visual perception design as its soul, and mutual design as its essence. A study has shown that culture-centred design of interface demonstrated very positive feedbacks from users [15]. Cultural patterns have significant influences on the product design conceptualization [14].

Although language certainly acts as the actual choice to note all strange thoughts, it is hard to be used to re-picture them ingeniously. Thus, there must be such transferring processes: thought-image-language, that is, the well-conceived image will perfect the effective language to convey the thoughts [8].

This study begins with the exploration of natural human face which is based on its physical information, through progressive levels of analysis methods, with adding semantic interpretation of POPF and capturing the changes of facial expression which conducted by natural facial motion, eventually form a new informative model of facial capture to light up the future research and application.

\section{Related work}

\subsection{Facial feature and facial expression}

Referring to the constitution of human face, the first thought is the physical features of the face. Physical features include not only the familiar features of the five human organs (ears, brows, eyes, nose and mouth), also the other features such as the shape of whole face, complexion, region and block etc. Besides, facial regions have very specific classifications of forehead, eye socket, cheek and jaw etc.; there are two method of region division of human face (See Table 3).

Scientists discovered that humans have 21 different facial expressions at least, in addition to the six basic common types (happy, surprised, sad, angry, disgusted) (See Table 4), There are happily surprised (happy and surprised), sadly angry (sad and angry) and other 15 types of complex expressions can be distinguished (See Table 5) [1].
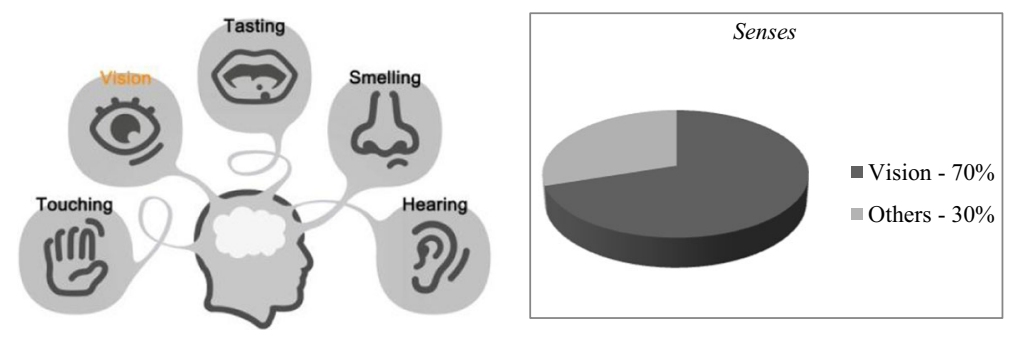

Fig. 2 The five senses and the sense of vision 
Table 3 Region division of human face

\begin{tabular}{llll}
\hline Method & Region 1 & Region 2 & Region 3 \\
\hline International & $\begin{array}{l}\text { T-zone } \\
\text { (A) }\end{array}$ & Left face & Right face \\
(B)
\end{tabular}

Scientists believed that people routinely pull 21 distinct faces - more than three times the long-accepted figure, and the study found most people express emotions with the same facial muscles. For instance, $99 \%$ of the time, people show happiness by raising their cheeks and stretching their mouth in a smile [2].

The photos were then analysed individually, to determine which facial muscles had moved to form the expression. This revealed clear differences in the way the 21 emotions were expressed (See Fig. 3). The analysis showed that the compound emotions are expressed by combining some of the features of the individual feelings [3].

Table 4 The six basic facial expressions

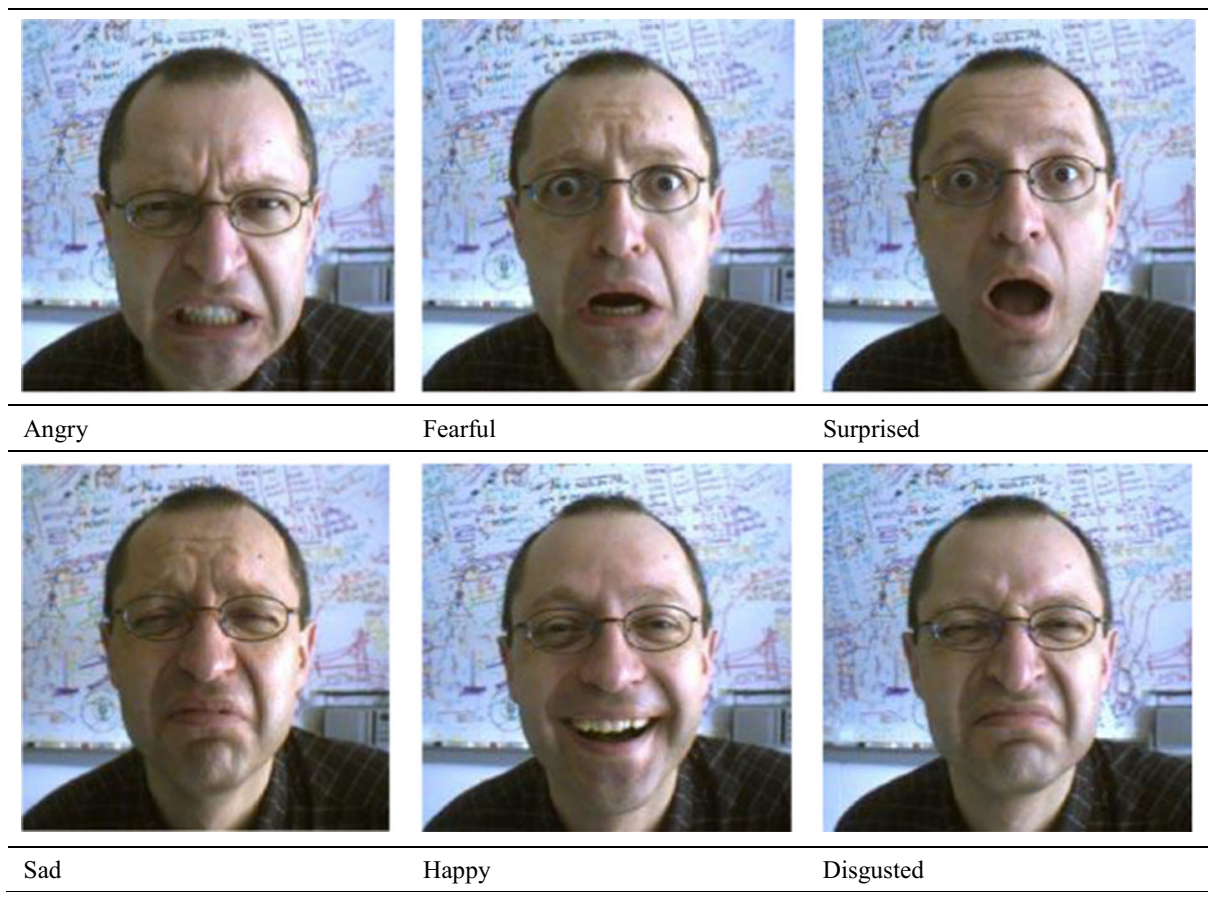


Table 5 The 21 complex facial expressions

\begin{tabular}{lll}
\hline Happy & Happily surprised & Fearfully surprised \\
Sad & Happily disgusted & Fearfully disgusted \\
Fearful & Sadly fearful & Angrily surprised \\
Angry & Sadly angry & Angrily disgusted \\
Surprised & Sadly surprised & Disgustedly surprised \\
Disgusted & Sadly disgusted & Hatred \\
Appalled & Fearfully angry & Awed \\
\hline
\end{tabular}

\subsection{Human motion}

Human motion can be considered as two aspects, the body motion and the facial motion. The facial motion can be illustrated by two parts, one is the physical feature of natural human face, and the other is the external reflection of internal emotion - the facial expression. The facial feature contains not only the five organs, also other important features.

There is a need to discuss the following concepts: the difference between the five organs and the five senses, the shape of whole face, the division of facial region. For the facial expression, there need to mainly discuss the changes of facial expressions with motions. The following concepts are: the constituted physical features of facial expressions, the motion ways and regulations of facial expressions with the changes of physical features, the selective analysis on the changes of physical features that pointed at several expressions which originally from different emotions $[6,16,18]$.

The presentation of the related research on body motion aims to show the current situation on motion capture of body and limb is mature enough. Besides, for the related research on facial motion, the list of current methods and applications aims to show that the current situation on facial motion capture needs to be improved. In addition, there also need to discuss the difference and the influence between motion and emotion, the differences are that one is external, another is internal; one is the expression of mood, another is the expression of feeling.

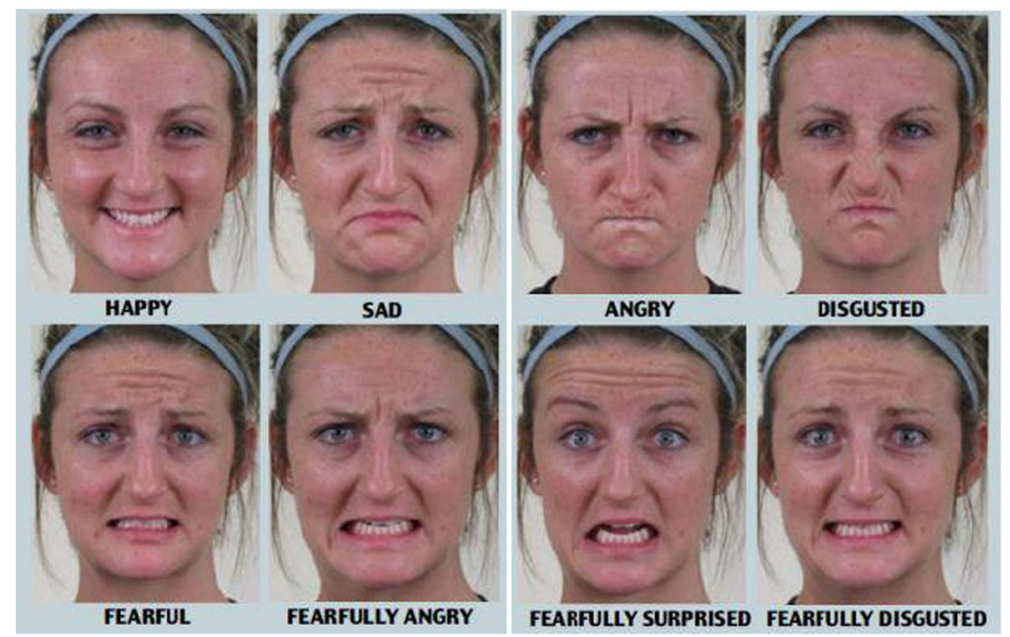

Fig. 3 The 21 emotions 


\subsection{Human motion capture}

\subsubsection{Body motion capture}

The techniques of body motion capture has already used in the film industry and the medical industry (See Fig. 4). For the film industry, the invented digital figure can act as an actual human with accurate movements. For the medical industry, Bionics designer Hugh Herr showed his incredible technology of artificial limb. He proved that there would be no such thing as "disabled", because bionics will bring about the end of disability.

\subsubsection{Facial motion capture}

Three digital platforms which used to capture information through marked point, blocked curve and blocked area [10].

\section{a. Realeyes}

Realeyes (See Fig. 5) is originally created at Oxford University, and uses Dr Ekman's six basic emotions at the core of its automated facial coding platform. It is the world's leading platform for measuring how people feel as they view video content. Thanks to the technological advances of cloud computing and the popularity of webcams, the platform is to construct an online coding system which can process and report results from all over the world in seconds, dramatically improving the viability of the technique and scaling its potential, and then audiences share their subconscious responses to content by simply using their webcam.

\section{b. InSight SDK - Individual Analysis Software}

InSight Software Development Kit (SDK) (See Fig. 6) is an individual face analysis software which uniquely combines emotion recognition, demographics and eye tracking technologies in one solution, all in real-time. It is able to track tiny movements of facial muscle in individuals' face and translate them into universal facial expressions like happiness, surprise, sadness, anger and more. Additionally, it is also able to accurately measure demographics like age, gender, ethnicity group, head pose and eye gaze location by using a simple camera.
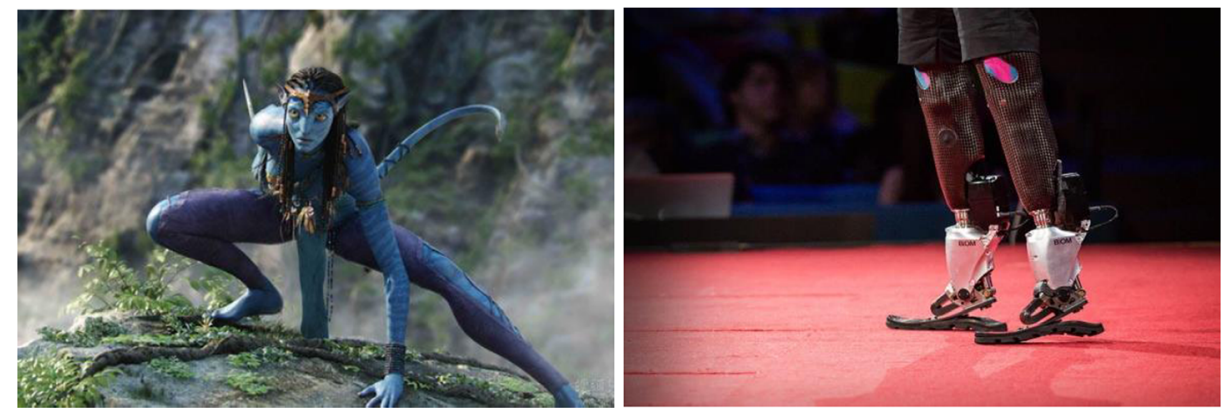

Fig. 4 The application of body motion capture: the image which is from the film of Avatar and the bionic limbs built by Hugh Herr 


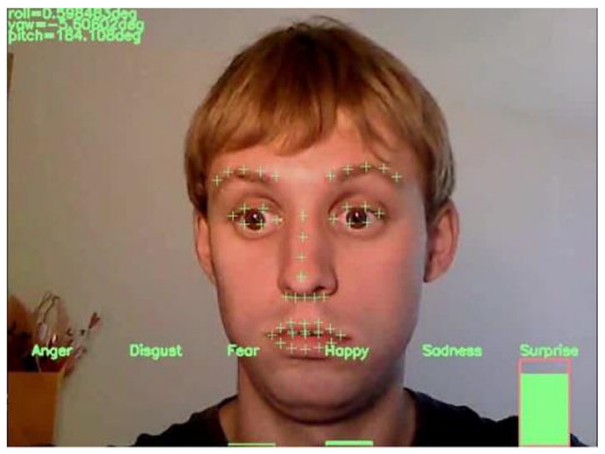

Fig. 5 The platform of Realeyes

c. SHORE $^{\mathrm{TM}}-$ Fraunhofer IIS

SHORETM (See Fig. 7) is short for the Sophisticated High-speed Object Recognition Engine; it is an image analysis system for object and face recognition, as well as extremely fine facial analysis. It culminated in a highly-optimized software library. Optimizing processintensive components using a variety of algorithmic and hardware-specific approaches makes it possible to process images in real-time. The foundation of the versatile SHORETM solution lies in our extensive experience with detection and analysis technologies and a large database for machine learning.

To sum up, body motion capture has already had matured techniques, but facial motion capture still has unmatured techniques. Therefore, there is need to develop a new model of facial motion capture.

\section{Methodology}

The most important keywords of the study are facial motion and POPF. In this study, the two aspects interact and influence each other, be their both starting points and assisted each other. It is necessary to get close contact with facial expression in terms of facial motion and visual information of POPF. Therefore, this research is starting from the related works and primary researches in order to identify the state-of-the-art in the culture inspired design in terms of design methods and processes.

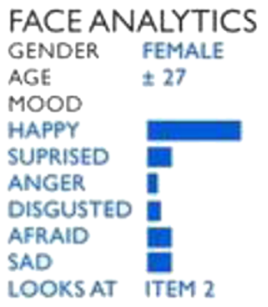

Fig. 6 The platform of InSight SDK

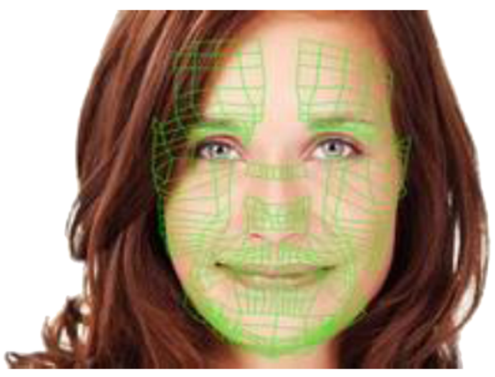




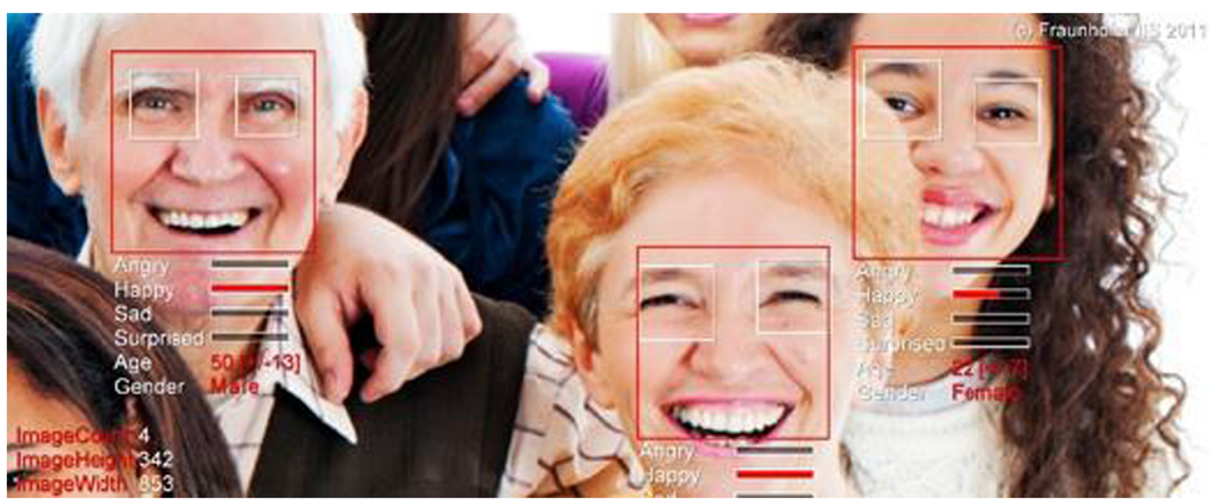

Fig. 7 The platform of SHORETM

\subsection{Systematic review based on related work}

The review was related to three main aspects of the study, and they are: facial features and expressions, human emotion and facial motion, the expression of visual information in POPF. The first aspect was to investigate facial features, including the five key features and the facial region division; because of the variety of human expression, to investigate what features and which areas affect and constitute the facial expression. The second aspect was to present the mainly influence that inner emotion impacted on facial motion and facial expression, to identify the certain regulation of motion which takes into account the facial distribution situation of sensory organs and muscles. The third aspect was to extract cultural semantics of POPF and visual information that constitute POPF, and to identify the expression method of visual information. Literature search provided the basic materials for this study, with through other methods and analysis, combined with the original design, finally constitute the whole research system.

For the literature review, an investigation of documental resources searching was explored with a series of keywords which are related to facial expression and facial motion at the beginning. Then it was extended to classify words with similar meanings or characteristics. After that, it was designed to search set-ups with the combination of keywords from different classifications.

\subsection{Data collection}

In order to identify existing applications without documental resources, the data collection contains two aspects. On the one hand, that was the related information about natural human face. First was to identify the physical features of natural face and explore the motion regulation. Owing to the changes of facial expression caused the facial motion, therefore it required to analyse the basic constituted elements and the motive ways of typical facial expressions. On the other hand, that was the facial information of POPF. It required to respectively discuss the motionless POPF and the motive POPF. Motionless POPF is the fixed illustration of POPF, the special face painting highly summarised typical characters and experiences of roles. Thus the study summarised visual information from POPF. Motive POPF is the changing of facial expressions with the painting of POPF during performances. The facial motion changed the facial expression, while the above POPF changed with them. 
Therefore, take the role of character in a certain play for example, the study considered the outstanding emphatic effects on physical features through facial painting, and the analysis of facial motion in several moments within the whole performance.

Besides, based on a collection of 272 painted faces, a semantics database of cultural elements of POPF from among its facial colours and characters, types and symbolic meanings was partially completed, which was sourced from certain typical and well-known illustrations of POPF.

\subsection{Observation}

Observation is a logical process from the outside into the inside. Firstly, the research on human face naturally starts with the outermost contour of face. Although there was no description of facial shape in POPF, there was clear description of it in real life. Besides, different shapes of face have different emotional meanings in recognition of traditional Chinese culture. In addition, though actor performs a certain role through the painted face, the selection of actor for different roles needs to be considered with practical reasons. Secondly, observational studied afore mentioned the shape of whole face, it is necessary to think about the facial complexion. In fact, the complexions of different ethnic groups can be distinguished very clearly, but the question is how to distinguish the people belonging to the same ethnic group? Or even in the same generation? And then, the answer can be found within POPF. Finally, after the facial shape and complexion, the facial region and boundary can be explored deeply. Everybody has the same types of features, but the expressions of features are different among types. It means that the expressions of blocks and profile lines are different. Through techniques of conceptual analysis, all above concepts have been recognized and came to the related supporting ideas.

\subsection{Case study}

The research selected several cases of POPF-themed and non-POPF-themed as key targets. For the basic facial elements, a certain description of features can be realised from the traditional culture and social cognition of China, and from the design of POPF as well. Thus, through observation and analysis, focused on the specific points-shape and color, the research has illustrated that the artistic techniques of expression proved the significance of information visualisation and the advantage of visual information, whether with the basis of aesthetic reason or functional reason.

\section{Findings \& results}

The study is based on four levels of knowledge, starting from the level of natural face, gradually analyse the effects on natural face in different levels with variety techniques of expression of POPF. Thus, the result of the study will explore a new method of facial motion research, and create a new research structure through the method.

\subsection{Level 1: natural human face without painting}

First level discussed the natural face without facial painting. 


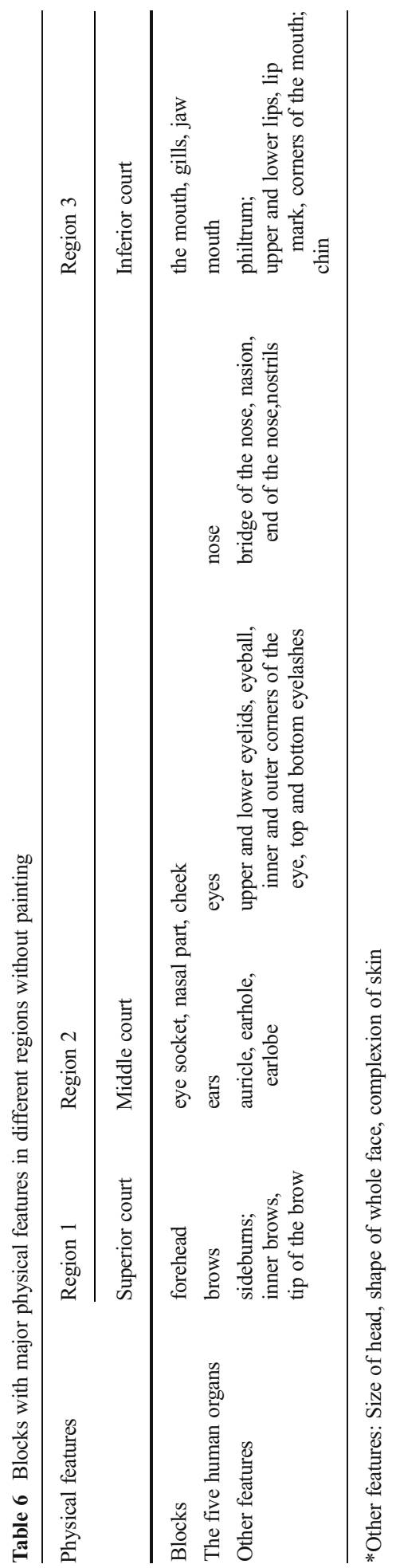


Table 7 Analysis of physiognomy with "The five features" in Chinese culture

\begin{tabular}{lll}
\hline Feature & Another name & Relationship with human life \\
\hline Ear & Listening organ & related to the longevity \\
Brow & Keeping organ & related to the health and the status \\
Eye & Monitoring organ & related to the strength of will and the moral nature \\
Nose & Identifying organ & related to the wealth and the health \\
Mouth & Telling organ & related to the happiness, benefit and fortune \\
\hline
\end{tabular}

\subsubsection{Major physical features of human face}

In the Table 6, all the detailed features are listed including blocks, key organs and others. Besides, in the Table 7, it shows the analysis of the five key features along with physiognomy meanings in Chinese culture.

\subsubsection{Facial expression and facial motion}

Facial expression is ultimately caused by facial motion, as a result of the deformation of blocks and profile lines. Facial motion is the origin of the deformation. In different facial expressions, the corresponding areas of face are different, and the effect and extent of areas' deformation are different. Certain facial expressions (See Tables 8 and 9) normally captured by quiescent states, along with the incessantly changing of facial expressions, the transition and switching between expressions is caused by the emotional changing. While the emotional changing acts, the facial expressions changes. Different external facial expressions caused by types of emotion. Specifically, the facial expressions are caused by the deformation of regional facial features.

For instance, someone who is 'happily surprised' moves all the muscles associated with showing surprise, and adds in a smile for good measure. People pull their face, apparently, when they receive some unexpected good news. In contrast, they reserve 'sadly angry' for someone whom they care about upsets them. Being appalled, involves feeling disgust and anger, with the emphasis on disgust, but this photo was not included in the grid. Hate involves the same two emotions but with more feeling put into the anger than disgust [11].

Table 8 Facial expression and facial motion [9]

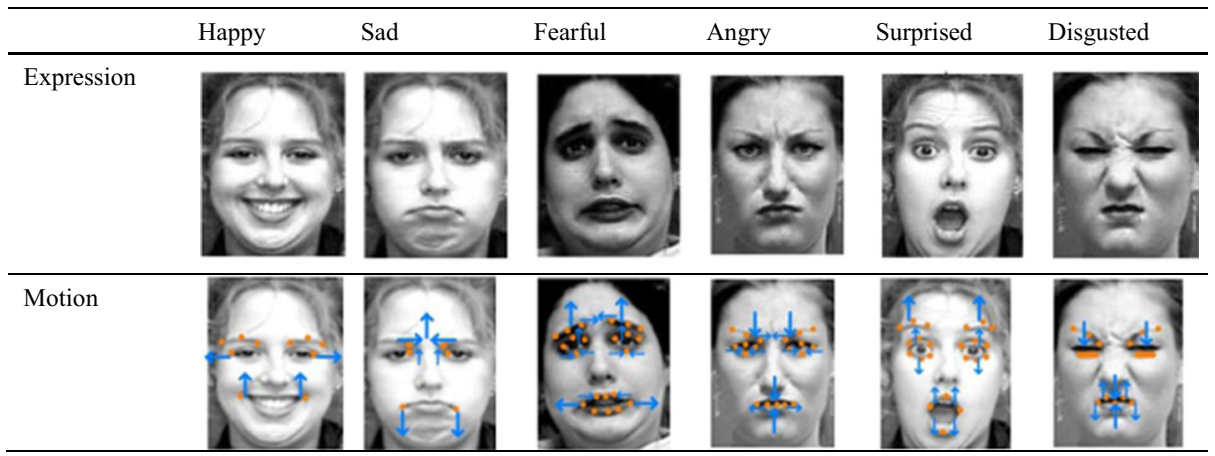




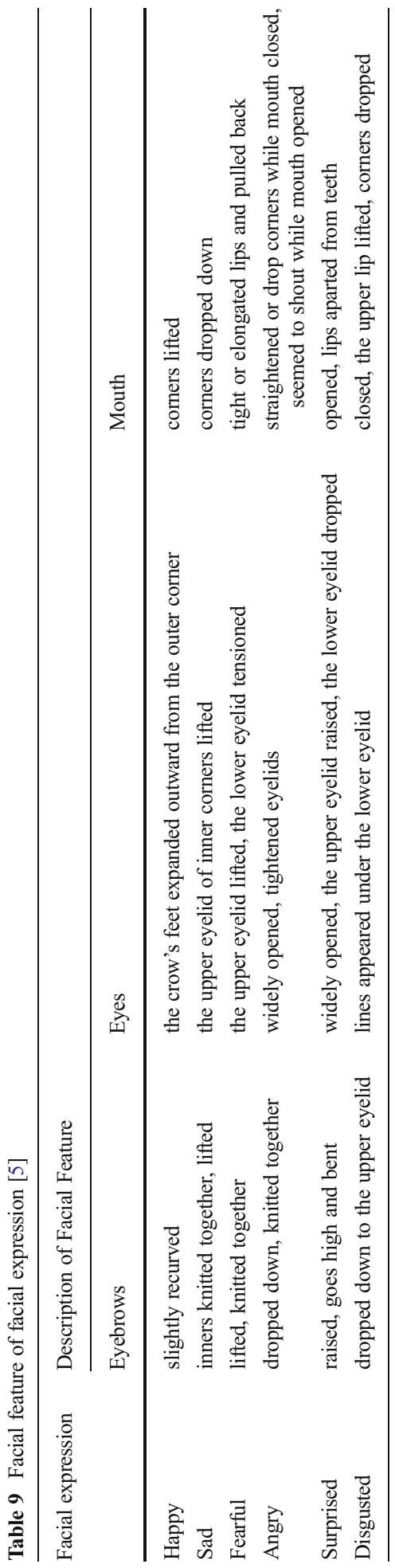


In these situations, people combine the scrunched up eyes and wrinkled nose of disgust, with the smile of happiness. Gaining a better understanding of our emotions could help treat conditions such as autism and post-traumatic stress disorder, as well as in the design of computerised aids for the disabled.

The Division of facial wrinkles and lines:

- To reflect Age: the height and curvature of the fishtail lines (crow's feet).

- To express Temperament: the fluctuation of the nasolabial folds (the curves flanking the mouth pit).

- To symbolise Person's Character: the pattern of the yintang line (A strip shaped like a gallbladder extending from the top of the nose ridge to the top of the forehead).

\subsection{Level 2: natural human face with painting - block}

Second level was on the basis of the first level, to discuss the regional divisions of natural human face with paintings.

\subsubsection{Shape of whole face}

There is no description about the shape of human face in POPF, but in fact, there are different divisions of this concept in the real world. The relatively simplest classification of facial shape is morphological classification. That is used to describe the facial shape by geometry. According to the theory of Pöch [13], the common 10 types of face through observation are oval face, round face, square face, rectangular face, diamond face, trapezoidal face etc. (See Table 10). Besides, there are wide variety classifications of painting and physiognomy theories in ancient China with the analysis of personality.

Oval face has the ideal shape for oriental women, and this face also has the most beloved shape by makeup artists. The overall impression is that the round face is more common for young or obese people; the square face is more common for men; the rectangular face is more common for tall and sturdy person of great stature. Thus, in the stage performance of Peking Opera, the selections of characters usually respect the customs and acceptances of the most people.

The concept of facial shape can evolve certain character meanings in Chinese traditional culture and cognition. For example, person with round-shaped face give a loyal feeling, while person with sharp-shaped face brings a sense of mean. Although the character meaning lacks of definite scientific evidence, it means something with symbolic imagination in human mind. Therefore, when choosing an actor for Peking Opera, combined with the characteristics of specific roles, the facial shape of the actor is usually an important factor.

Regardless of the facial painting in Peking Opera, actual human are quite often to use makeup to beautify their faces, especially their facial shapes. Though this method is mostly motivated by aesthetic reason, it can be explained that people has a certain awareness of meanings which evolved by the facial shape.

\subsubsection{Shape and profile line of block}

Begin with the whole facial shape, and then look into the regional shape, facial painting makes obvious regions with outstanding boundaries between each others. First of all, for the transition 
Table 10 Facial shape vs. character

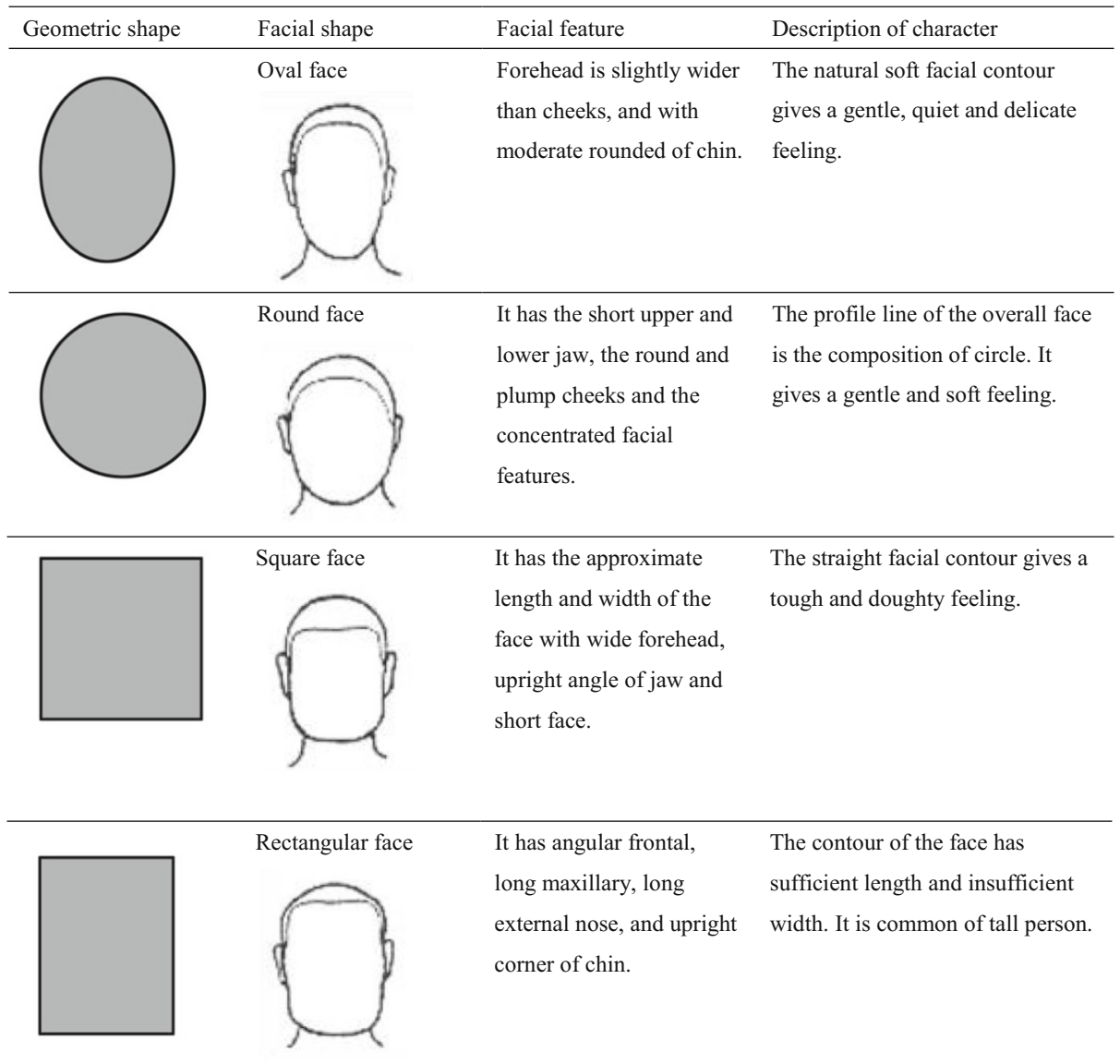

and division between regions, a tangible method in POPF is to highlight the profile line with drawing. The drawings of the majority amount of painted faces are located in the same regional position, because of the five connatural organs. Compared to the natural human face, the difference of POPF is to additionally express the life experience of this character.

Besides, regardless of the facial painting in Peking Opera again, in real life people often use makeup to highlight theirs key facial features. Take a very simple example, when only one person facing you, his/her appearance could be recognized easily. However, if a group of people appears in the front of you, it would be not easy for recognizing one face quickly. Therefore, through the makeup, such as outlined eyeliner, eyebrow and lip lines, the technique of emphasizing the profile line makes the more particular and outstanding facial appearance

\subsection{Level 3: natural human face with painting - colour}

The third level was based on the second level, when the natural face of the first level, plus the regional stresses of the second level, this level was to discuss the meaning of additional colours after the completion of regional division. 
Table 11 Facial colours v.s. characters

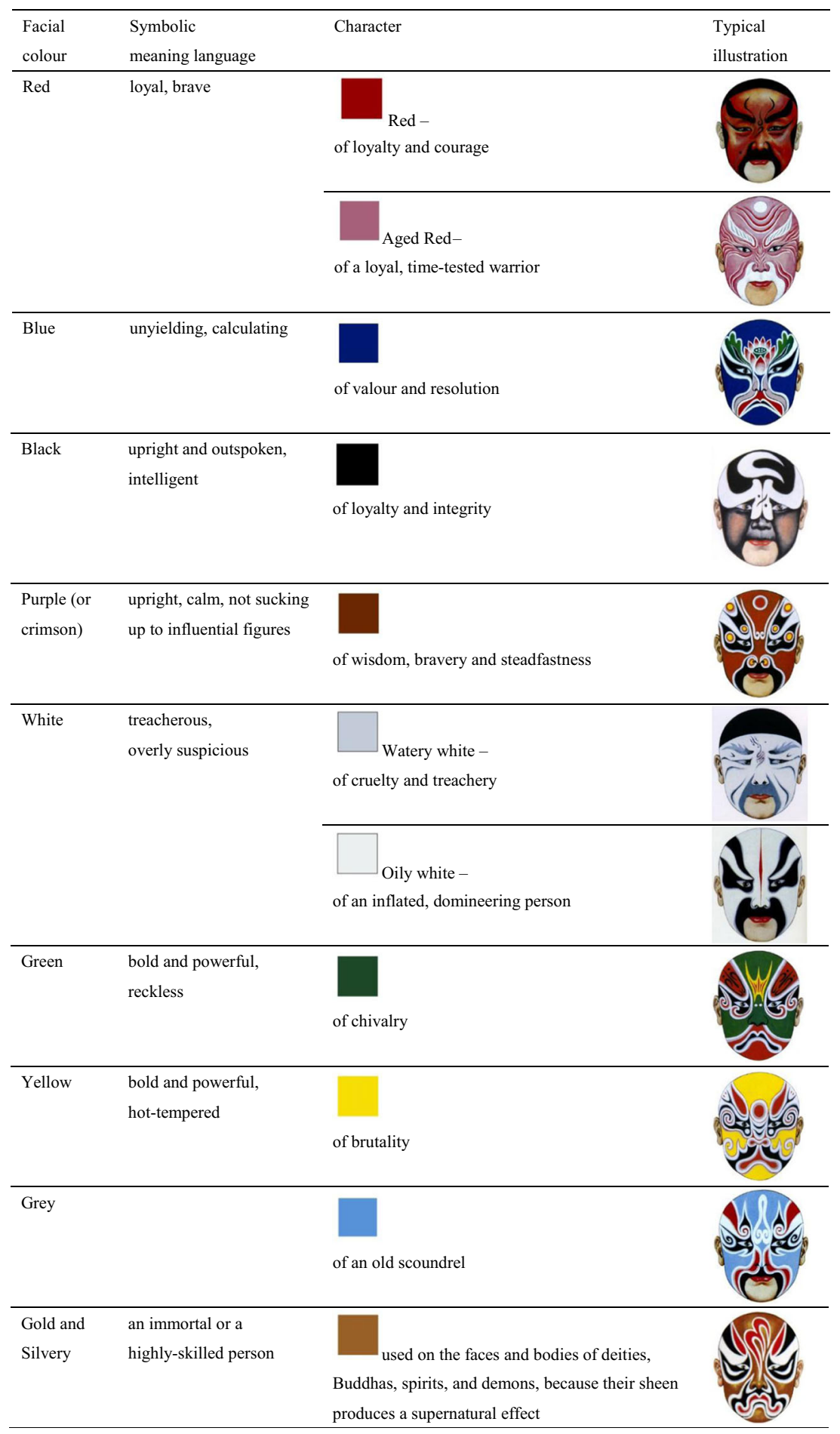




\subsubsection{Complexion and colour zone}

As far as natural complexion is concerned, according to the ethnic groups, there are only three types: white, yellow, and black. Thus, the difference of people that belonged to different ethnic groups was really obvious. However, concerning one person, it is too general to describe the facial colour, because the complexion of ethnic skin is a rather general summarisation. For a specific person, the facial colour is not constant. Actually, the facial colours of different region are slightly different, but the difference is invisible because of the natural transition of complexion. The expression of colour in POPF can convey further more symbolic semantics.

\subsubsection{Colour v.s. character}

The facial colour of POPF can express the natural complexion of roles, moreover, the more than ten kinds of facial colour endowed with the corresponding characters by using exaggerated artistic methods (See Table 11). In POPF, certain one colour is a particular indication of certain one character, while a certain colour depending on some other factors will be

Table 12 Visual expression of physical information in POPF

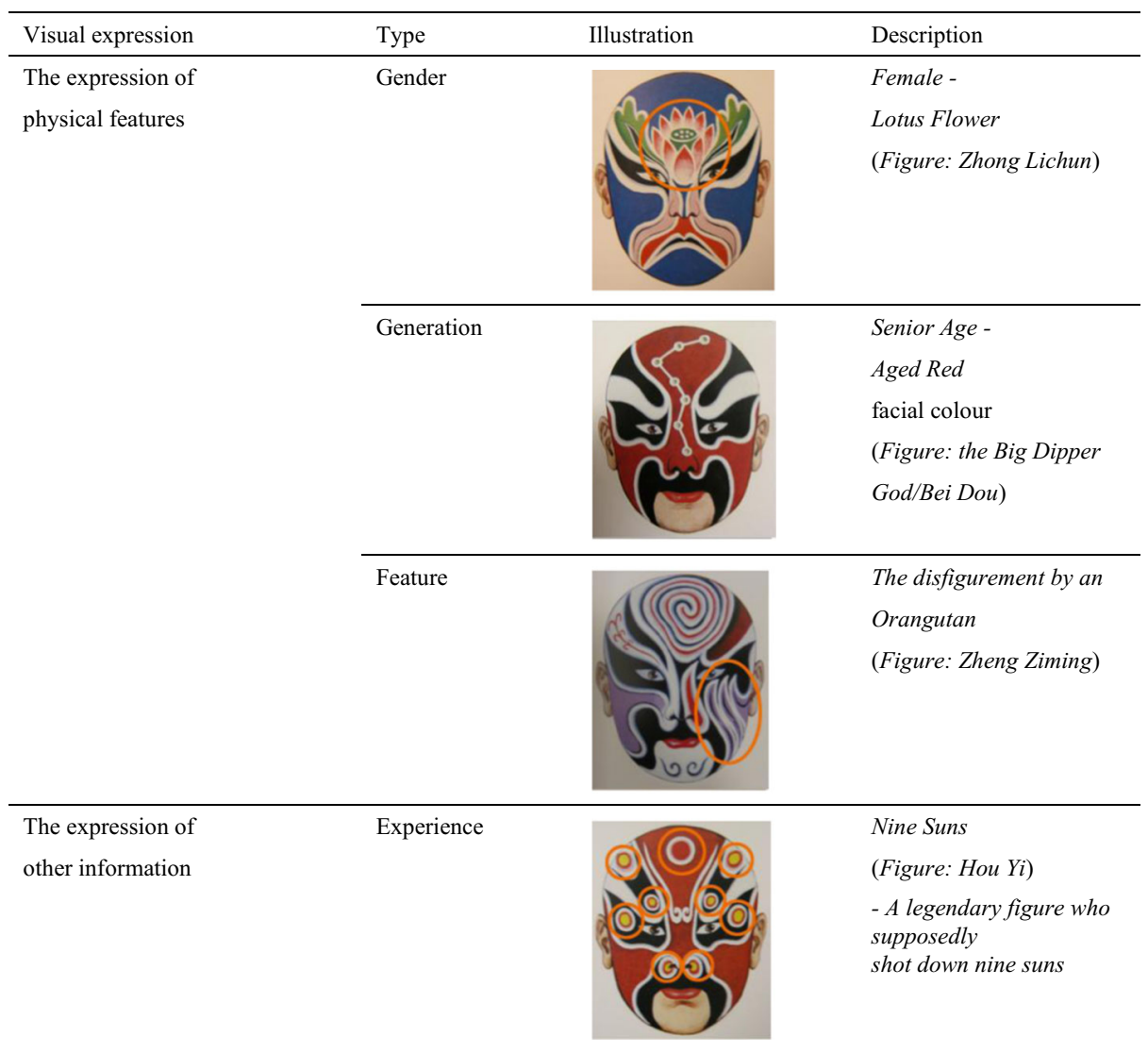


transformed for different roles. Thus the mixed colour occurred and derived from the changing of chroma and intensity of the single colour.

As above mentioned, it is very easy to identify complexions between different ethnic groups, but it is hard to identify the physical features within the same ethnic group, such as the age of generations. The POPF provides different techniques for expressing natural semantics. For example: aged red comes from red, red is the colour of loyalty, and aged red is used to represent senior warriors.

\subsection{Level 4: motion of painted face (during performance)}

The final level was based on the former three levels. POPF highlights profile lines and colours of natural human face. With the facial motion of natural face, and combined with the special techniques of expression, it achieved the motion of painted face which is driven from the natural facial motion during the stage performance. Thus, the overlapped effects of the double motions make the audience easily understand the emotional change of roles.

POPF is composed by the natural human face without painting, the emphasized areas and the colours. As far as the role of characters in Peking Opera is concerned, the illustration of

Table 13 Visual expression of chemical information in POPF

\begin{tabular}{lll}
\hline Visual expression & Type & Description \\
\hline $\begin{array}{l}\text { The expression of } \\
\text { chemical reactions }\end{array}$ & $\begin{array}{l}\text { Suspicious Eyes (Figure: } \\
\text { Cao Cao) }\end{array}$ \\
Knitted Brows \\
- worry too much \\
(Figure: Lian Po)
\end{tabular}

Emotion

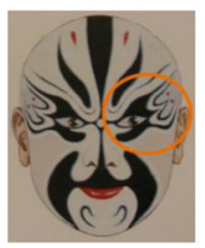

Smiling Eyes

(Figure: Niu Gao)

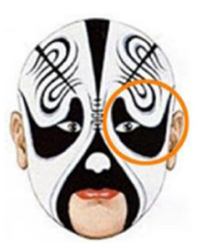

Sad-looking Eyes

(Figure: Xiang Yu) 


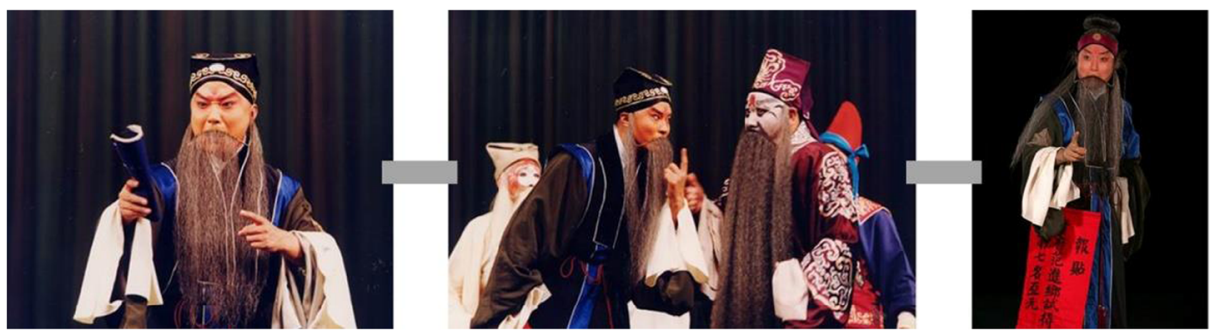

Fig. 8 Three scenes of the play

POPF for typical role is unique, but the characteristics of the role is multiple and changeable, it means that one role cannot be summarised by one illustration of POPF. Therefore, the detailed deformation of POPF which affected by facial motions makes further expressions of this character, and also emphasizes the advanced effects of painting.

In addition, painted faces of one character are changeable. On the one hand, sometimes it is required to emphasize the influence of particular occasions or special status in different plays. On the other hand, for drawing the painted faces, different artists may add or revise some details based on their own different understanding of the same character.

The visual expressions in POPF can be regarded in two groups (See Tables 12 and 13). One is to express physical information including the physical features which can be directly recognised from the outer skin. Another is to express chemical information, it means the related influence starting from the inside body.

The play of Fan Jin Passing the Examination (See Fig. 8) is from the Chinese novel The Scholars. The character Fan Jin does not painted by rich colors, just simply emphasised at the forehead and the eye socket. Compared to the whole face covered with paintings, this example makes audience to identify facial expressions of the actor easily. Because the face has highlighted facial features and quiet coloured background in basically. The following three typical scenes was selected and accompanied different facial expressions in different situations (See Fig. 9).

As can be seen from the first scene, the character is excited and depressed, because he has repeatedly failed the examinations before with bad living conditions. Originally, he was painted with the red colour at ophryon. Due to a sudden frown, the expression makes the person look even more depressed. While in Chinese traditional culture, the dark colour of ophryon means impending disaster. Thus, his expression with painting can be understood through clearly showing with facial motions which are the dropped knitted brows and the outstretched face.

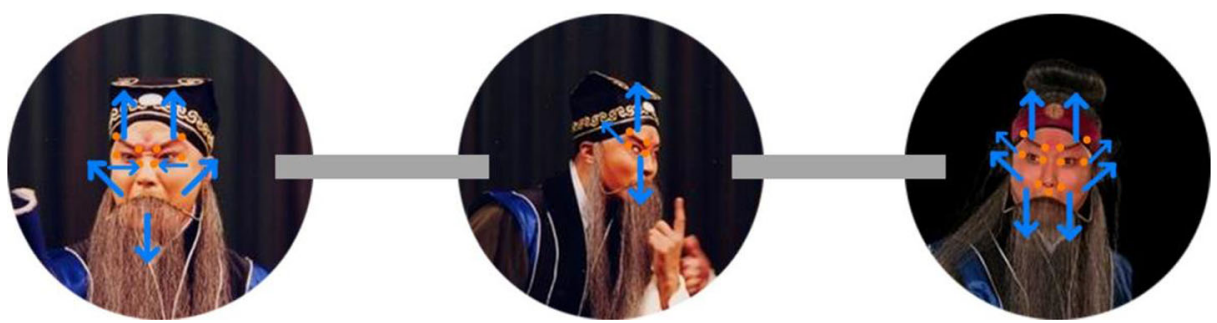

Fig. 9 Facial motion in three scenes 
As can be seen from the second scene, the character has a skeptical look, because he thinks that he might be received the bad news of failed his examination. Originally, he was painted slender eyeliners extending from the corner of eyes. In order to express his doubts, the slightly closed eyes made eyeliners extended even more.

As can be seen from the third scene, the character is surprised and excited, because he can finally confirm that he passed the examination. His excitement and mania can be noticed from his expressions at the same time. All the facial features are presenting a trend of expansion, while the eyebrows, the eyes and the cheeks are upward obliquely. Thus the highlighted facial painting has improved the emotion of excitement, and also looks a sense of madly excited.

\section{Discussion}

\subsection{The relationship of still and active expression in POPF}

The natural facial motion without painting, plus the facial motion with the mapping of POPF, and then the overlapped double motion can express the deeper meanings of visual information. For the natural human face, the physical changes of facial expression are visible, but the chemical changes of human emotion which is caused by mental activities are nearly invisible, it means that it produced a loss of the effect from the inside to the outside.

Table 14 Analysis of cultural elements (typical illustrations of POPF)

\begin{tabular}{|c|c|c|c|c|}
\hline \multirow[b]{2}{*}{ Illustration } & \multirow[b]{2}{*}{ Figure } & \multicolumn{3}{|l|}{ Cultural elements } \\
\hline & & $\begin{array}{l}\text { Facial colour } \\
\text { V.S. the } \\
\text { characteristics } \\
\text { of specific role }\end{array}$ & $\begin{array}{l}\text { Type of the } \\
\text { painted face }\end{array}$ & Symbolic meanings \\
\hline & $\begin{array}{l}\text { Dou Erdun } \\
\text { in } \\
\text { Stealing the } \\
\text { Imperial } \\
\text { Steed }\end{array}$ & $\begin{array}{l}\text { Blue: } \\
\text { valor and } \\
\text { resolution }\end{array}$ & $\begin{array}{l}\text { Three-tile face: } \\
\text { (The flowered } \\
\text { Three-tile face) } \\
\text { A bold warrior or a } \\
\text { green-wood hero }\end{array}$ & $\begin{array}{l}\text { Two halberds: Wrinkles } \\
\text { Yintang (The gall-shaped figure): } \\
\text { Prowess } \\
\text { Weapon pattern: The deadly } \\
\text { two-hook weapon }\end{array}$ \\
\hline & $\begin{array}{l}\text { Bao Zheng } \\
\text { in } \\
\text { The Un- } \\
\text { grateful } \\
\text { Husband }\end{array}$ & $\begin{array}{l}\text { Black: } \\
\text { of loyalty } \\
\text { and integrity }\end{array}$ & Black full face & $\begin{array}{l}\text { The white knitted brows: } \\
\text { loyalty to country and concern for } \\
\text { the welfare of the people / } \\
\text { underscoring the judge's ironclad } \\
\text { integrity and strict observance of } \\
\text { the law } \\
\text { The white crescent: } \\
\text { the mysterious powers possessed by } \\
\text { this judge, who tries in the upper } \\
\text { world by day and in the } \\
\text { netherworld at night [4]. }\end{array}$ \\
\hline
\end{tabular}


For example, the temperature of face will rise when people feel nervous, and along with the flushed complexion. In fact, this changing of facial colour is very tiny, and it is still unobvious that ignoring the individual factors. However, in terms of scientific facts, the muscles will be in slightly taut when people feel nervous, thus the actual result should be the rigid facial motion. Besides, it is possible to convey the emotion of anger with the same of heated facial skin and flushed complexion. Thus, the two types of emotion cannot be distinguished by the single one factor of complexion. Therefore, the study discussed with the former second and third levels. Owing to the obvious changes of facial features when people feel nervous and angry, such as the bending angle and extent of eyes and brows, that was why the study started from the first level of the physical feature, then considered the region and shape, and then considered the colour.

On the other hand, POPF could be regarded as an artistic processing for the physical features of natural human face, includes clear division of region and vibrant color. Thus, the capability of visual expression was determined by the emphasis of physical facial features in POPF. During the performance of Peking Opera, the overlapped effects of artistic processing, plus the motion of POPF, finally reflected both sides of the physical feature and the chemical reaction.

\subsection{The methods of facial motion capture}

The proposed new motion capture method is to paint the face with different colors on different facial regions with distinct boundary lines similar to POPF, instead of placing the facial

Table 15 Analysis of symbolic meanings (typical patterns)

\begin{tabular}{|c|c|c|c|c|}
\hline \multicolumn{2}{|c|}{ Symbolic meanings } & Painted faces & Signs and & Meaning languages \\
\hline \multirow{2}{*}{$\begin{array}{l}\text { Socially } \\
\text { endowed } \\
\text { aspects }\end{array}$} & Skills & & $\begin{array}{l}\text { Nine Suns } \\
\text { (Figure: Hou Yi) }\end{array}$ & $\begin{array}{l}\text { He was a legendary } \\
\text { figure who supposedly } \\
\text { shot down nine suns. }\end{array}$ \\
\hline & Status & & $\begin{array}{l}\text { The character for } \\
\text { 'King' } \\
\text { (Figure: Huyan }\end{array}$ & $\begin{array}{l}\text { He was a Xiongnu } \\
\text { chief. }\end{array}$ \\
\hline \multirow{2}{*}{$\begin{array}{l}\text { Physical } \\
\text { features }\end{array}$} & Gender & & $\begin{array}{l}\text { Lotus Flower } \\
\text { (Figure: Zhong } \\
\text { Lichun) }\end{array}$ & $\begin{array}{l}\text { This image on the } \\
\text { forehead of her } \\
\text { respectively symbolise } \\
\text { female warrior. }\end{array}$ \\
\hline & $\begin{array}{l}\text { Disfigure- } \\
\text { ment }\end{array}$ & & $\begin{array}{l}\text { The disfigurement } \\
\text { (Figure: Li } \\
\text { Keyong) }\end{array}$ & $\begin{array}{l}\text { His forehead scratched } \\
\text { by an eagle. }\end{array}$ \\
\hline
\end{tabular}


markers in the classic facial motion capture. Ordinary video will be recorded instead of using expensive motion capture equipment, for the participants. Because of the distinct color and boundary, the analysis of facial motion video images will be much easier.

\subsection{Connections between visual expression and POPF}

The analysis of symbolic semantics of POPF is a procedure of deconstructing and decoding the POPF. Among the procedure, a complete illustration of POPF can be split into a plurality of combinational part, which is a process from the surface to the point. A painted face represents a role of character, while its various components represent various characteristics of this character, for example: general character, specific background status, a special experience, a certain physical feature, even a certain associated object with the character. After the refined analysis, the POPF has become particularly vivid, and it provides all the information that need to be known by audience during performances (See Table 14). Besides, this way of information transmittion is the most intuitive and fastest [17].

Existing design methods of information visualization are summarized into two categories:

Based on the symbolic semantics of POPF, compared with the research gap and the research aim, the connection between them was established and design principles and transforming methods among similar painted arts and cultures with using similar symbolic expression ways to POPF was found. The most popularity of current transforming methods is "Side-effect transforming" like deforming part of patterns, changing colours, adding textures with the using of body tattoo and stage performances (See Table 15).

Besides, the most of current existing products simply used the traditional meanings of POPF or mapped the entire illustrations of POPF, fewer amounts of products was designed with transforming methods through setting up the connections between the component parts of the painted face and the function of the products.
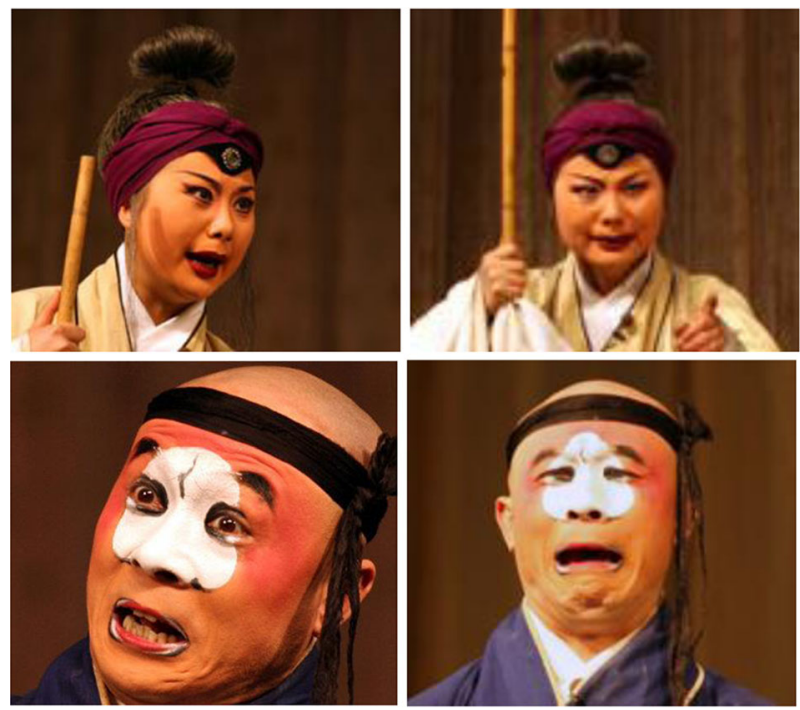

Fig. 10 Compound emotions in POPF ('Fearfully Angry' and 'Sadly Surprised'). Figure: Zhang Yi and his foster mother, from the play of Indiscreet 


\subsection{Common features for both natural face and POPF in expressing emotions}

Painted faces in Peking Opera as an advanced method to express facial features of natural human can illustrate both basic expressions and complex expressions. While the natural human has compound emotions in real life (Compare to Fig. 3), the POPF shows the emphasis and the changing of compound emotions in stage performances (See Fig. 10).

As human nature, the facial motions for the same category of an emotion are the same between the natural face and POPF because the actors still need to express an emotion as natural as possible even in a play. Therefore, the muscle movement direction will be similar

Table 16 Basic facial expressions of natural face and painted face in POPF

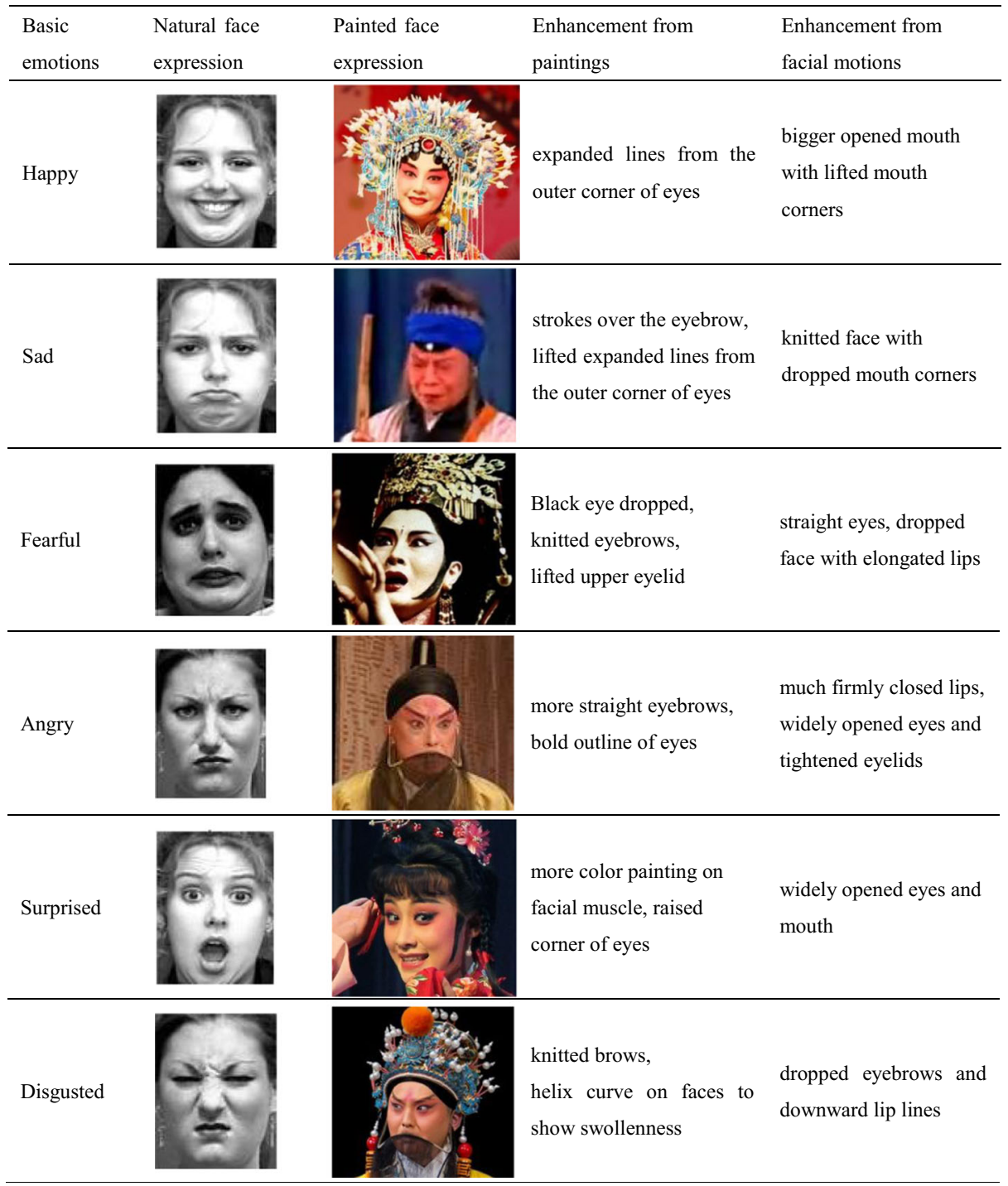


although the emotion could be enhanced by emphsised facial motion scales and facial paintings. The differences will be in the sizes of facial motions and semantic effects of paintings. The facial motion in natural faces in general is more gentle compared the motion in POPF. Table 16 shows the common features and differences in expressing emotions from natural face and POPF.

\section{Conclusion}

POPF is a visual form of information transmittion in the Peking Opera; while other nonPeking-Opera-themed illustration is using other visual forms. Thus, the effectiveness of visualisation reflected out with the comparison with other ways of information transmittion. Visual communication is the most intuitive, and spread the most correct information to people. Once a visual signal is widely known, its effect is much greater than a character signal. Because the readability of text depends on people's level of education and the capacity of understanding, but the current widely used visual signal just expressed by simple colors and shapes, and it is easily understandable. This research, through four levels of progressive studies, showed that POPF conveys emotions more effective than non-painted faces.

POPF is used to express the soul of character; it needs to convey the physical feature of character, but also to summarise the character with unique and easily identifiable symbolic methods; so that it could be understood intuitively by people. Besides, natural human face can only be perceived by the physical features without painting. Thus, the painting like POPF makes even more meanings for the character.

The research presented a model of facial motion capture which abandoned the tracking method of marked points. Although the collected data less than the latter, it shows the more clear changes of facial expressions. One hand is that POPF offers the clear division of regions and vibrant colours, the other hand is the innovative aspect of the research - the dual facial motion makes the more clear and explicit effects on transmitted information.

\section{Future application}

POPF as a nonverbal communication provides visual information through image digitalized way. Compared to the number digitalized way which expressed low-level semantics, the symbolic semantics of POPF provides a high-level expression for human facial information.

Throughout the basic necessities of human beings, nothing can leave without visual communication. For example, the designs based on Peking-Opera-themed are including conceptual design, information design, system design and computer game design, etc. However, a few products are the re-design of applications starting from the truly deeper semantics of POPF. In fact, most of current brands have one or several distinctive logo or image. Then sometimes people choose to remember their icons, rather than their names; because a distinctive icon can be accurately kept in the mind. Therefore, new application of POPF would be a really aesthetic and functional design.

The new designed model of this research started from the cultural-based visual expression and the facial motion capture. Thus, it must be explored new functions of 
facial expression recognition through a great deal of database of facial motion capture. Currently, the facial expression recognition was used as a way of marketing. Marketers usually observe facial expression from customers while facing their products or promotions. But now, in order to match the technological level of modern society, the new modal could be applied to select and reorganise the feature elements through coding data or modelling motion. Besides, the modal could be applied to revised the design of virtural characters in computer games or animated films; because the model could be regarded as a toolkit to capture facial information.

The combination of facial motion capture provides great help for the further research. Application of such a culture resource may include product design, interaction design, system design and information design in China and Western countries, along with the integration of other elements of traditional Chinese cultures and arts.

Open Access This article is distributed under the terms of the Creative Commons Attribution 4.0 International License (http://creativecommons.org/licenses/by/4.0/), which permits unrestricted use, distribution, and reproduction in any medium, provided you give appropriate credit to the original author(s) and the source, provide a link to the Creative Commons license, and indicate if changes were made.

\section{References}

1. Darwin CR (1872) The expression of the emotions in man and animals, 1st edn. John and Murray, London

2. Ekman P, Friesen WV (1978) The facial action coding system: a technique for the measurement of facial movement. Consulting Psychologists Press, Palo Alto

3. Ekman P, Friesen WV (1986) A new pan-cultural facial expression of emotion. Motiv Emot 10:159-168

4. Fu X (2009) Peking opera painted faces. Baihua Literature and Art Publishing House, Tianjing

5. Horton WL (1994) The icon book: visual symbol for computer systems and document. Wiley, New York

6. Jin H, Gao W (2003) Analysis and application of the facial expression motions based on eigen-flow. J Softw 12(14):2098-2015

7. Leong BD, Clark H (2003) Culture-based knowledge towards new design thinking and practice - A dialogue. Massachusetts Institute of Technology. Design Issues, pp 48-58

8. Li Z, Zhang X, Kang G (2008) A comparative study of literary images between Chinese and English from the cognitive perspective. CCSE: Asian Soc Sci 4(8):102

9. Liu IT (2012) The role of emotion between emotional and symbolic expression. J Shu-Te Univ 1(14):185-216

10. McDuff D, Kaliouby RE, Senechal T, Amr M, Cohn JF, Picard RW (2013) Affectiva-MIT Facial Expression Dataset (AM-FED): naturalistic and spontaneous facial expressions collected in-the-wild. IEEE Computer Society Conference. Portland USA. In CVPRW'10

11. Michael JL, Shigeru A, Miyuki K, Jiro G (1998) Coding facial expressions with gabor wavelets. In: Proceeding of Third IEEE international conference on automatic face and gesture recognition. Nara Japan. IEEE Computer Society, pp 200-205

12. Ouyang L, Jiang R (2011) The analysis and research of visual perception and image processing in visual information design - take google earth for example. IEEE Image Analysis and Signal Processing. Hubei. In IASP'2011, pp 336-339

13. Pöch HR (1916) Bericht über die von der Wiener anthropologischen Gesellschaft in den K.u.k. Kriegsgefangenenlagern veranlassten Studien. Mitt Anthrop Ges In Wien 46:107-131

14. Razzaghi M, Ramirez M, Zehner R (2009) Cultural patterns in product design ideas: comparisons between Australian and Iranian student concepts. Des Stud 30(4):438-461

15. Shen S, Woolley M, Prior S (2006) Towards culture-centred design. Interact Comput 18(4):820-852

16. Wang D (2014) The significance of information visualisation based on the symbolic semantics of Peking Opera painted faces (POPF). IEEE Automation and Computing. Cranfield. In ICAC'14, pp 83-87

17. Wang L, Li R, Wang K, Chen J (2014) Feature representation for facial expression recognition based on FACS and LBP. Int J Autom Comput 5(11):459-468

18. Yang C, Chiang W (2008) An interactive facial expression generation system. Multimed Tools Appl 1(40):41-60

19. Zhao M (1997) Peking opera painted faces, 2nd edn. Morning Glory Publishers, Beijing 


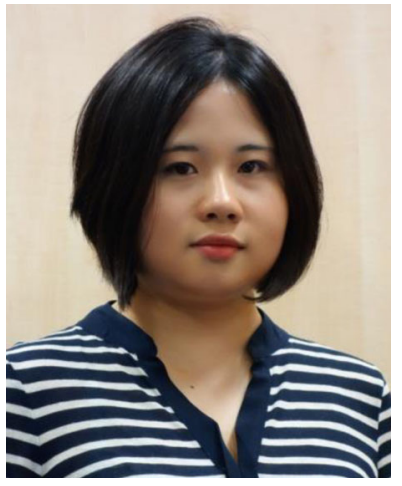

Ding Wang is a PhD Design Research student at College of Engineering, Design and Physical Sciences, Brunel University London, UK. She obtained her BEng degree in Industry Design from Beijing University of Technology in China in 2009 and MSc degree in Integrated Product Design from Brunel University London in UK in 2011. She is working on the semantic features of cultural elements proceeding from Chinese traditional arts and crafts, and the cultural-based applications include product design, information design, interaction design, service design etc. Her research interest is on product design solutions and design inspired visual communication solutions.

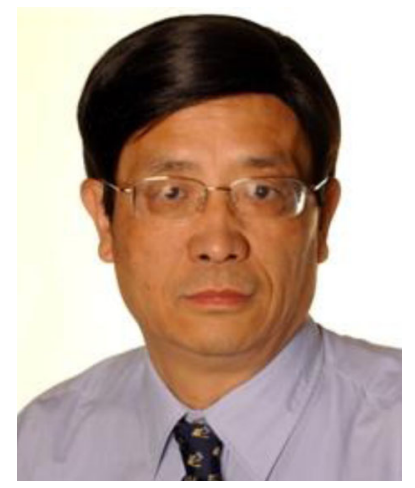

Dr Jinsheng Kang is a Senior Lecturer at the College of Engineering, Design and Physical Sciences, Brunel University London, UK. He is a Chartered Engineer (CEng), Member of IMechE, and Fellow in The Higher Education Academy. He obtained his BEng degree in Mechanical and Manufacturing Engineering in China in 1982 and his $\mathrm{PhD}$ degree in Mechanical Engineering in the UK in 2001. He joined Brunel University as a Lecturer in Design in 2003. He was an Academic Visiting Scholar in the Department of Mechanical Engineering, University of Washington, Seattle, USA from 1986 to 1988, in the Department of Manufacturing Engineering, Loughborough University, UK from 1996 to 1997, and in the Center for Human Modelling and Simulation (HMS), University of Pennsylvania, USA in summers 2008 and 2009. His research interest is currently focused on the application of human modelling and simulation in the areas of product design and environment design. 


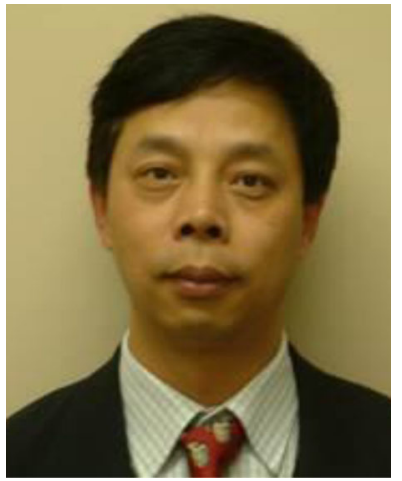

Dr Sheng-Feng Qin is a Reader in Product/Industrial Design with an extensive career in design academia. Prior to joining Northumbria School of Design in January 2014, he was a Senior Lecturer in Department of Design at Brunel University London, UK. He obtained his BSc and MSc degrees in China and his PhD degree in CAD from the University of Wales, UK. He was an academic visiting scholar in 1996-7 at the University of Birmingham. Following the visiting, he took a Research Assistant post in 1998 at the University of Wales Institute Cardiff and subsequently joined Loughborough University as a PostDoc Research Associate in 2000. His research interests include crowdsourcing-based design, digital design and CAD, culture-inspired design, sketch and visual computing, interaction and interface design. Dr Qin is a member of IEEE.

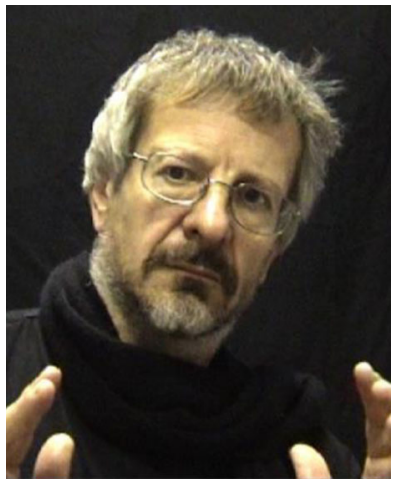

Prof Johannes Birringer is a choreographer/media artist and co-director of DAP-Lab at Brunel University where he is a Professor of Performance Technologies in the School of Arts. The DAP-lab (www.brunel.ac.uk/ dap) focuses on research in performance, interactive systems and wearable design. He has created numerous dance-theatre works, video installations and digital projects in collaboration with artists in Europe, the Americas, China, Japan and Australia. He has published widely on the performing and media arts; his books include Theatre, Theory, Postmodernism (1989), Media and Performance (1998), Performance on the Edge (2000), Performance, Technology and Science (2009), and two edited volumes on Dance and Cognition (2005), and Dance and Choreomania (2011). 